\title{
A comparison of cemented paste backfill shotcrete barricade design methods
}

\author{
RL Veenstra Newmont Australia, Australia \\ X Zhao The University of Western Australia, Australia \\ AB Fourie The University of Western Australia, Australia \\ JJ Grobler Newmont Corporation, USA
}

\begin{abstract}
The use of cemented paste backfill (CPB) is becoming increasingly more common at underground mines worldwide. Part of any CPB design includes the specification of the (typically) shotcrete barricades that retain the CPB within the stope during filling. Newmont's Tanami Operations (NTO) has started an in situ barricade stress monitoring program. The data from this program will provide a basis for comparison of several models that can be used to model the capacity of these barricades. These models vary in complexity from analytical solutions to $3 D$ numerical models. Part of the comparison will include a discussion detailing the required material inputs and how these inputs were obtained. Analysis of this comparison will provide additional understanding on what parameters affect the ultimate capacity of a shotcrete barricade.
\end{abstract}

Keywords: backfill, barricade, shotcrete, instrumentation, modelling

\section{Introduction}

Cemented paste backfill (CPB) is an increasingly utilised material for backfilling underground mine voids (generally referred to as stopes). Essentially, CPB is a combination of tailings, water, and a binding agent (generally some sort of general Portland cement blend), which is mixed together to produce a paste. During this material's early curing ages, it behaves like a non-Newtonian fluid, meaning that it is capable of being reticulated to an underground stope using gravity or through the assistance of a pump. Additionally, this fluid-like behaviour allows the material to flow throughout the stope void as additional CPB enters the stope. However, this fluid-like behaviour also means that the CPB would flow out of the stope unless it was retained by a structure. It has become common practice for this retaining structure to be built out of shotcrete.

Part of any CPB pour design includes the specification of these shotcrete structures or barricades. Barricade designs vary from mine to mine, but some generalisations can be made. They are typically arched towards the direction of loading where possible, with shotcrete thicknesses typically varying between 0.2 and $0.4 \mathrm{~m}$. It is uncommon for these structures to have steel reinforcement in Australia, but reinforcement is more common in other parts of the world.

As these barricades need to retain the CPB while the stope is backfilled, they need to be capable of withstanding the backfill loads. There are two types of loading: gravitational and pressurisation. The first means there is a disconnect between the reticulation system and the CPB within the stope, and any barricade loading comes purely from the mass of CPB that is filling the stope. The second is when the CPB is pressurised by something besides its own self weight (i.e. the fill mass is intentionally or unintentionally connected to the reticulation system during a tight fill or the crown or sidewall of the stope fails and the inflow of that rock pressurises the stope, etc.).

This paper will look at several methods of determining the capacity of shotcrete barricades, ranging from analytical methods to simple 3D numerical models to fully time-dependent 3D numerical models. 


\section{Onsite data collection}

This paper uses stope and barricade geometries based on those used at Newmont's Tanami Operations (NTO). This includes data obtained from two stopes at NTO: the 073L and the 100D. NTO currently uses a primary-secondary mining sequence with a generalised single-lift stope size of $20 \mathrm{~m}$ wide by $30 \mathrm{~m}$ long by $40 \mathrm{~m}$ high. Single to triple-lift stopes are common at NTO.

For a typical drive, NTO shotcrete barricades are built using a prefabricated $5 \mathrm{~m}$ radius arch framework. There are larger radius arches available for wider drive sizes. Shotcrete thickness is nominally $0.2 \mathrm{~m}$ with extra thickness being placed on all the abutments. The shotcrete is cured for a minimum of 24 hours in order to achieve a minimum unconfined compressive strength (UCS) of $16 \mathrm{MPa}$.

The NTO's current pour design calls for the placement of a plug up to a nominal height of $9 \mathrm{~m}$. This is allowed to cure to a minimum UCS of $100 \mathrm{kPa}$ (an industry rule-of-thumb based on work completed by Clough et al. (1989)). After the plug CPB has reached this strength, the rest of the body is poured.

\subsection{In situ stress monitoring}

The in situ stress monitoring undertaken involved installing instruments in the undercut of the stope to measure the stresses within the CPB and within the shotcrete of the barricade to measure the barricade stresses. Directional convention for the instrumentation (and for this paper) is that the $x$-direction is perpendicular to the drive, the $y$-direction is parallel to the drive (perpendicular to the barricade), and the z-direction is vertical.

Figure 1 summarises the installation for both stopes. The instrumentation cluster for measuring the in situ CPB stress consisted of three orthogonally placed total earth pressure cells and a single piezometer. Instrumentation was installed at two locations: immediately upstream of the shotcrete wall (red circles in Figure 1) and the other as close to the centre of the stope as feasible (blue or green circles). In both stopes, there were two instrument clusters installed immediately upstream in location. One cluster was installed at approximately $0.5 \mathrm{~m}$ height and the other at approximately $2 \mathrm{~m}$ height. The $073 \mathrm{~L}$ had two instrument clusters installed at the brow (green circles in Figure 1) whereas the 100D only had one instrument cluster installed, which was placed on top of the safety berm (blue circle in Figure 1). The right-hand-side (RHS) photograph, shown in Figure 1, is an upstream view along the drive into the stope, and shows the two sets of instrumentation separated by the exclusion berm.
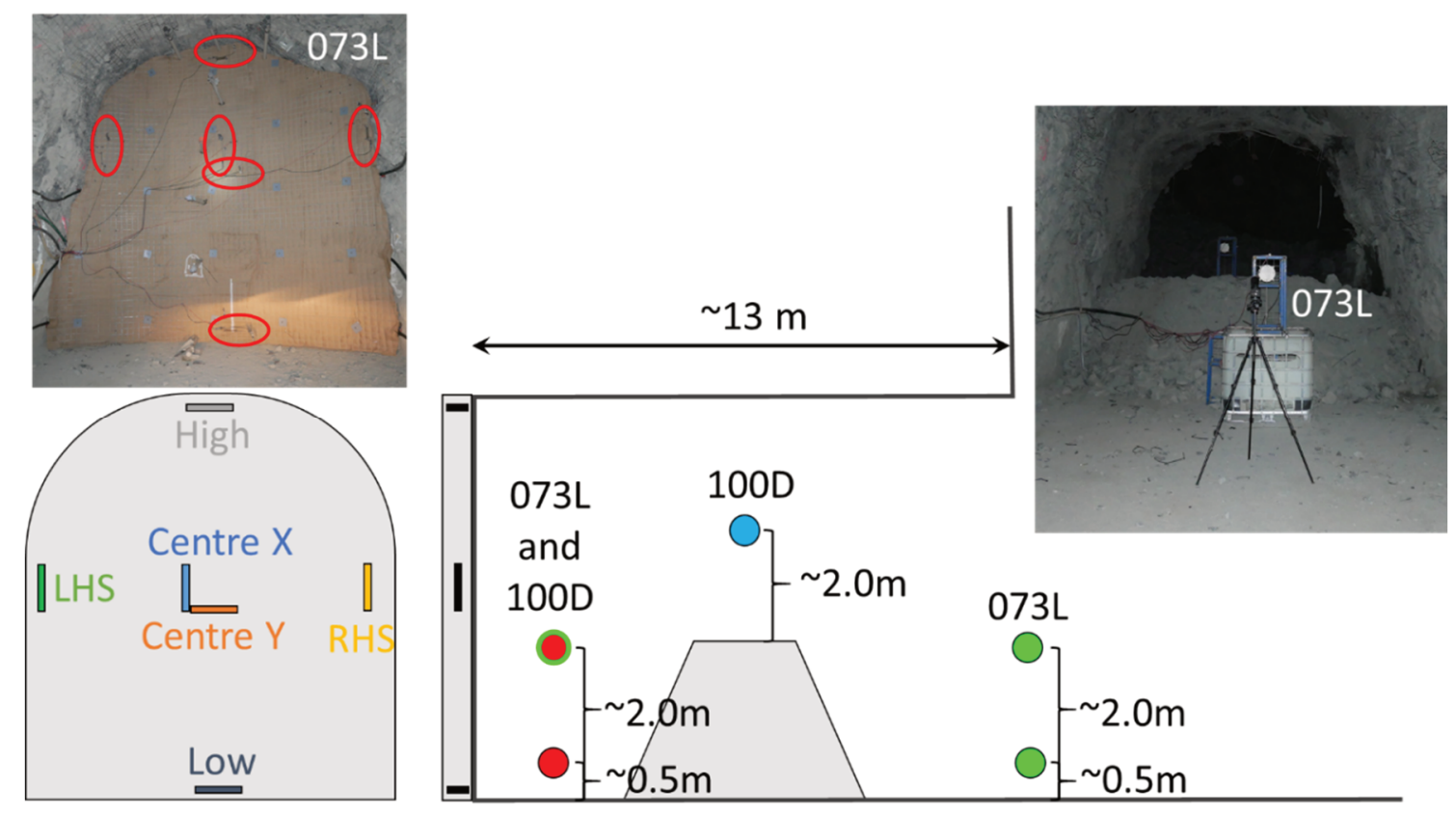

Figure 1 Schematic of the 073L and 100D in situ instrumentation 
The instruments installed within the shotcrete barricade were 'new Austrian tunnelling method' (NATM) cells, designed to measure stress changes in shotcrete. The NATM cells were installed along the horizontal (x-direction) and vertical (z-direction) centrelines of the shotcrete wall. The locations are colour-coded and labelled on the schematic.

Figure 2 presents the in situ monitoring results for the first 20 days of pouring in the $073 \mathrm{~L}$ and the 100D. These figures compare the $y$-direction CPB pressure (perpendicular to the barricade) measured at the highest instrument close to the wall (the red dot with a green line) versus the in situ shotcrete stresses (the in situ shotcrete stresses are colour-coded to the schematic in Figure 1). It is readily apparent that stresses in the $073 \mathrm{~L}$ barricade were higher despite similar loading pressures. The expected reason for this difference is that the shotcrete in the 100D barricade was significantly older than the $073 \mathrm{~L}$ at the start of filling ( 7.5 days versus 1.5 days). It is also interesting that the loading pressures were similar as the stopes had different CPB level rise rates, binder contents, and geometrical configuration.
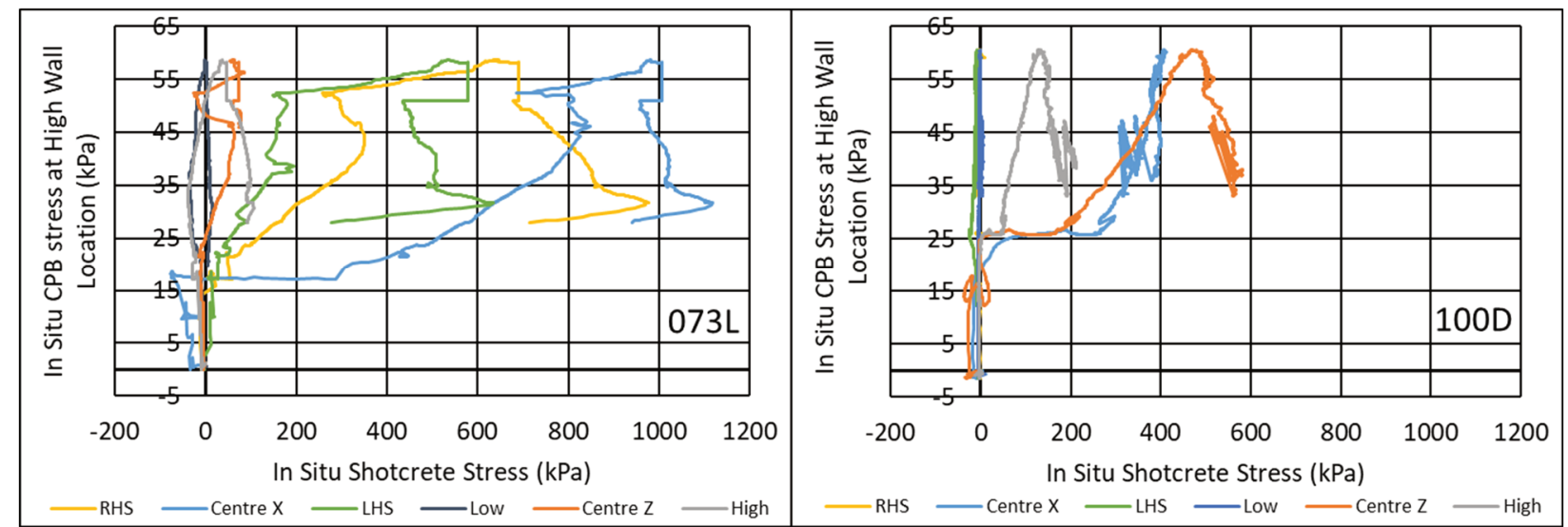

Figure 2 Plots from the 073L and 100D instrumentation showing the in situ shotcrete stresses versus the loading pressure recorded at the highwall location within the cemented paste backfill fill mass

This figure also shows that a barricade needs to experience approximately $18 \mathrm{kPa}$ of pressure load before the shotcrete starts to exhibit compressive stress (in both cases it was a large increase at the Centre X location). Before this, however, both walls were experiencing tension. It is also interesting that the barricade's highest stresses come from different spatial locations. Both walls show high Centre $X$ stresses. However, the high 073L stresses are all from the horizontal measurement locations (the RHS and left-hand-side (LHS) abutments) whereas the $100 \mathrm{D}$ stresses are from the vertical measurement locations.

\subsection{Surveying barricade as-builts}

As part of the instrumentation program, a purpose-built 3D LiDAR scanner (seen in Figure 1) was used to develop as-builts of the installed walls. This involved scanning the drive before the framework was installed, scanning the drive and the framework prior to shotcrete being installed, and then scanning the shotcrete after it was sprayed. The combination of these scans allowed a more accurate view of the wall to be developed, particularly pertaining to the wall's orientation, the shape of the arch, and both overall and spatial shotcrete thickness. An example of this is shown in Figure 3. This figure shows isometric, plan, and RHS views of the shotcrete wall as-builts for both stopes. 

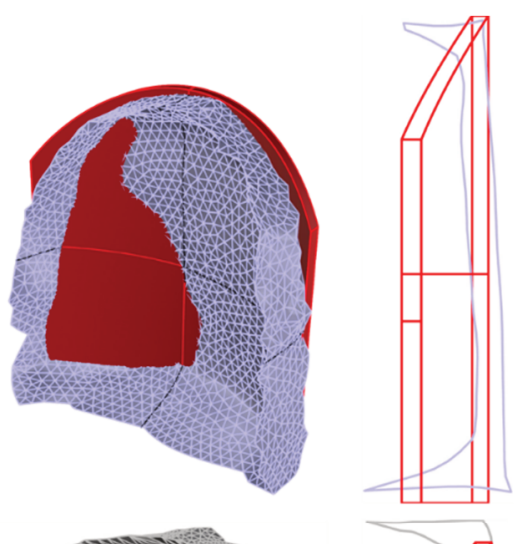

\section{L}
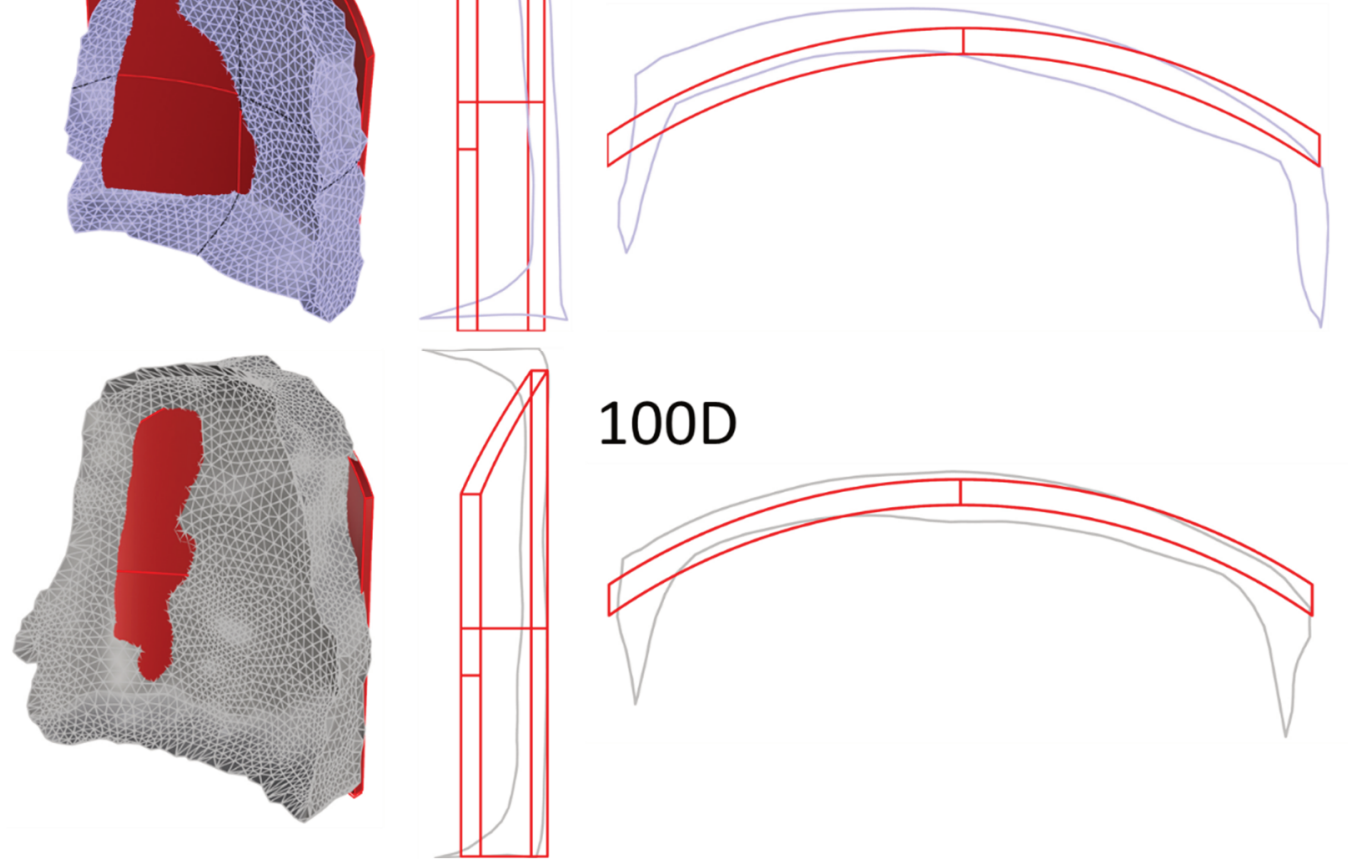

\section{$100 \mathrm{D}$}

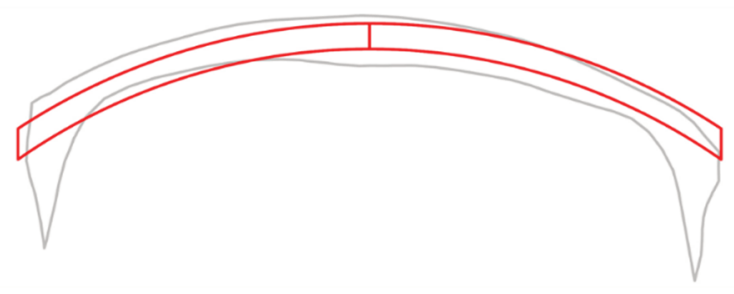

Figure 3 073L (purple) and 100D (grey) shotcrete wall as-builts (isometric, and vertical and horizontal cross-sections through at the centre of the wall) generated from LiDAR scanning. Red wireframe is a 'typical' design shape for a Newmont Tanami Operations shotcrete wall

The red wireframe is for a 'typical' NTO shotcrete wall design shape. A comparison of this shape to the as-builts shows that the orientation of both walls is not ideal. The readily apparent issue is that both walls are misaligned, with the LHS of both walls being further into the stope than the RHS. This misalignment is more pronounced in the $073 \mathrm{~L}$ wall than the $100 \mathrm{D}$ wall ( $\sim 7^{\circ}$ rotation compared to $\sim 3^{\circ}$ rotation, respectively). Both walls are also inclined vertically, with the $073 \mathrm{~L}$ wall pitched $\sim 4^{\circ}$ backwards and the $100 \mathrm{D}$ wall pitched $\sim 4^{\circ}$ forwards. The 100D wall is also larger than the $073 \mathrm{~L}$ wall in both dimensions and volume.

The upstream arch shape was consistent in both walls due to the use of a prefabricated arch framework. The overall thickness is relatively consistent in both walls though thin points do exist. However, the 073L shotcrete abutment (particularly the LHS) were not as evenly shaped as the abutments of the 100D wall.

\subsection{Material properties}

As part of this work, the time-dependent behaviour of NTO's CPB and shotcrete needed to be determined. These properties were determined from laboratory or literature data.

\subsubsection{Cemented paste backfill}

Most mix design test programs have limited early age strength data, with this data being obtained from 1- and 2-day UCS tests. However, as barricades are loaded by early age CPB, it is important to determine how a CPB gains strength over the first 24 to 48 hours. Therefore, a more detailed effort was conducted to determine how the CPB's strength changed over this time period. This was accomplished by using a shear vane equipped rheometer to obtain multiple measurements as the sample cured and comparing these to UCS tests cast from the same material that were conducted when possible. Figure 4 is a summary of these test results and how the early age results tied into the later age results. The red box highlights where both UCS and shear vane results were obtained. 


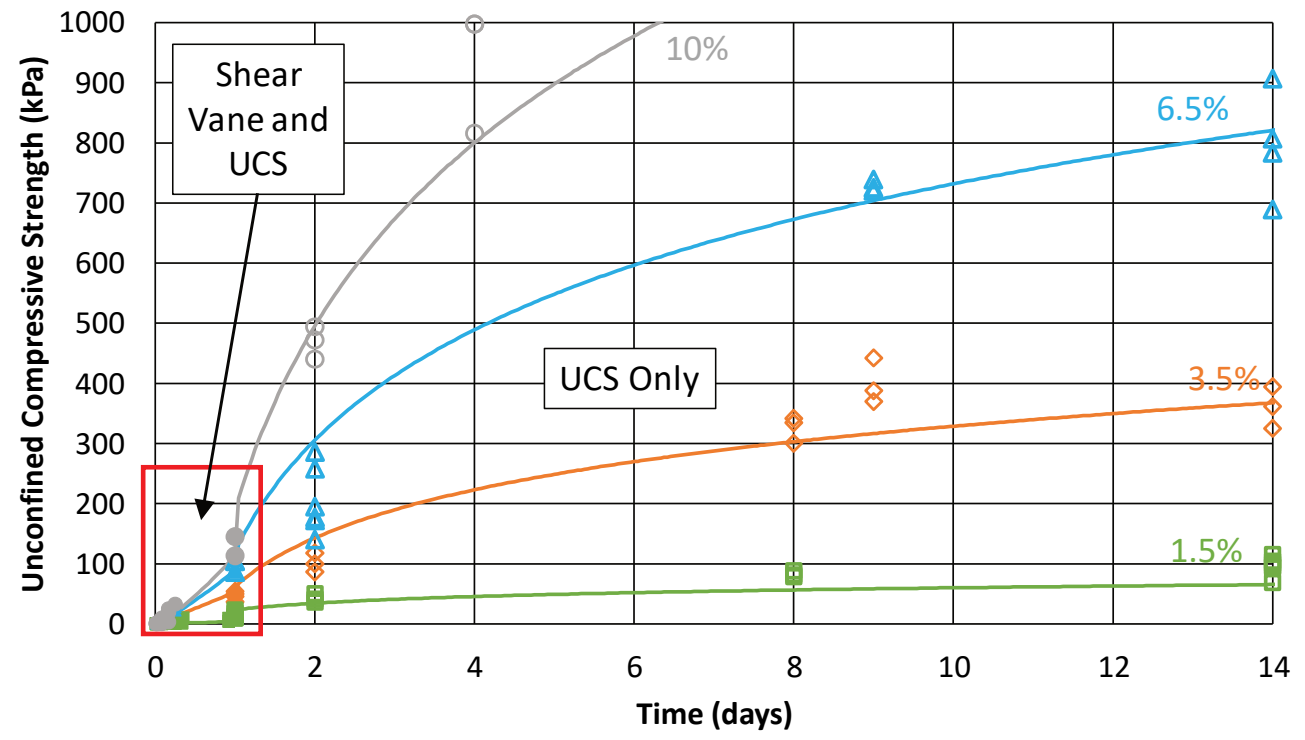

Figure 4 Plot showing time-dependent unconfined compressive strength (UCS) gain with increased curing age for different binder contents

Note that both the shear vane and UCS test determine a shear stress which, if using a Mohr-Coulomb failure criterion, is composed of a friction angle and a cohesion. A typical NTO mix design also includes multiple triaxial tests on samples that are 14 days or older. This allows the relationship to be determined between UCS, friction angle, and cohesive strength. By combining the test results and the in situ CPB stress results, it was possible to determine the time-dependent material behaviour of the early age CPB.

\subsubsection{Shotcrete}

Normal NTO procedure involves the testing of each shotcrete wall prior to the commencement of pouring to determine if the shotcrete strength meets its requirement of $16 \mathrm{MPa}$ after a 1-day cure. However, the NTO's onsite laboratory equipment does not allow the friction angle, cohesive strength, or post-peak behaviour to be determined. Due to this, the shotcrete input parameters were developed using both NTO's database and shotcrete triaxial data presented in Saw et al. (2009). A comparison of the UCS results from both datasets (Figure 5) shows that the UCS averages are similar.

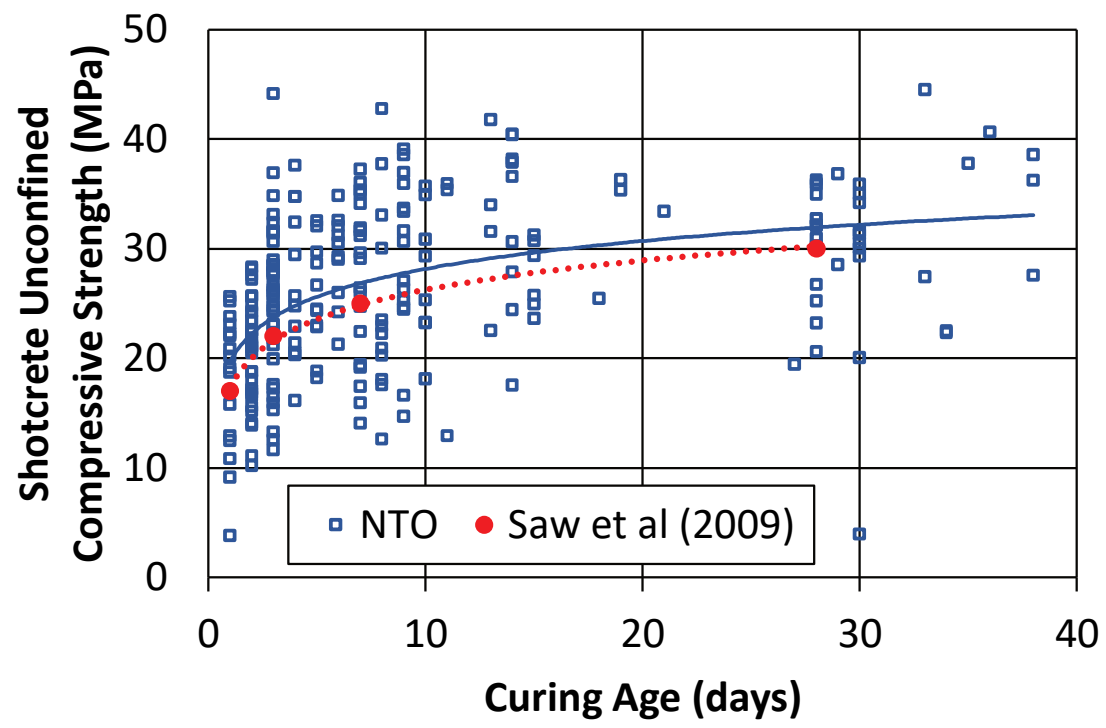

Figure 5 Unconfined compressive strength (UCS) shotcrete data from NTO compared to average UCS shotcrete data from Saw et al. (2009) 
In a similar manner to the CPB testing, the triaxial data was used to determine the relationship between UCS, friction angle, and cohesive strength. The tensile strength was assumed to be $10 \%$ of the UCS. Additionally, the post-peak modulus, residual friction angle, and cohesive strength were determined.

\subsection{Fill modelling versus instrumentation}

Using the time-dependent CPB and shotcrete material properties, both the $073 \mathrm{~L}$ and 100D stopes were modelled using a methodology adapted from methodology presented in Veenstra (2013). Figure 6 compares the instrumentation and model results. The upper graphs compare the instrumentation and model results for the stress that is perpendicular to the barricade (y-direction). The lower graphs compare the in situ shotcrete stresses. Solid lines are the instrumentation stresses and dashed lines are the modelled stresses. The black lines show the change in backfill levels during filling.
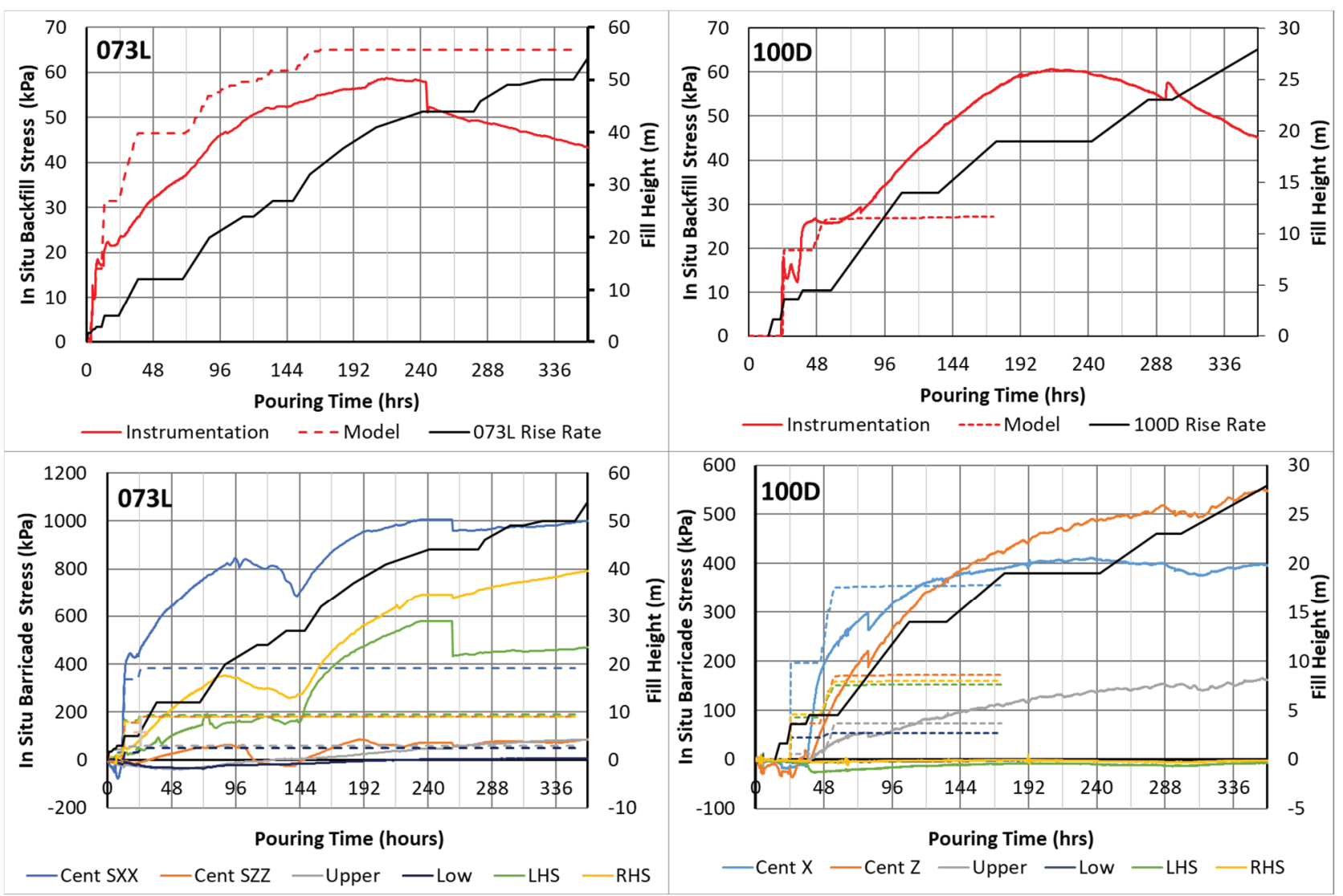

Figure 6 Comparison of instrumentation and model results from the barricade instrumentation cluster and the in situ shotcrete instruments

There is generally good agreement between the instrumentation and the modelled data, particularly prior to the models reaching the brow of the stope (approximately 36 hours and 52 hours for the $073 \mathrm{~L}$ and 100D stopes respectively). After the CPB reached the brow, the modelled data shows very little stress increase with additional loading. It was decided to use this relationship for future modelling.

The maximum pressure experienced by the $073 \mathrm{~L}$ or $100 \mathrm{D}$ barricades was around $60 \mathrm{kPa}$. Table 1 presents a survey of drive stresses perpendicular to the barricade (i.e. what loads the barricade) measured upstream of the barricade. These vary from 50 to $140 \mathrm{kPa}$. It is expected that substantially higher loading pressures will be required to cause a barricade to yield. An examination of barricade capacity will be examined in the next section. 
Table 1 Literature survey of in situ stress within cemented paste backfill drives

\begin{tabular}{|c|c|c|c|c|c|}
\hline Mine & Stope & Source & $\begin{array}{l}\text { In situ } \\
\text { stress (kPa) }\end{array}$ & $\begin{array}{l}\text { Approximate } \\
\text { distance from } \\
\text { barricade }(m)\end{array}$ & Comments \\
\hline DBS & 073L & - & 60 & 2 & - \\
\hline DBS & 100D & - & 60 & 1.5 & - \\
\hline $\mathrm{CBI}$ & $715-N 22$ & $\begin{array}{l}\text { Thompson et al. } \\
\text { (2012) }\end{array}$ & 90 & 2 & $\begin{array}{l}\text { Pour stopped at } \\
\text { barricade design capacity }\end{array}$ \\
\hline $\mathrm{CBI}$ & 715-N18 & Veenstra (2013) & 140 & 4 & $\begin{array}{l}\text { Pour stopped at } \\
\text { barricade design capacity }\end{array}$ \\
\hline $\mathrm{CBI}$ & 745-N5 & Veenstra (2013) & 90 & 3 & - \\
\hline CBI & $685-N 20$ & $\begin{array}{l}\text { Thompson et al. } \\
\text { (2011a) }\end{array}$ & 50 & 2.5 & - \\
\hline Williams & 9500 L70-5 & $\begin{array}{l}\text { Thompson et al. } \\
\text { (2011b) }\end{array}$ & 70 & 5 & - \\
\hline Kidd Creek & 67-SL1 & $\begin{array}{l}\text { Thompson et al. } \\
\text { (2011a) }\end{array}$ & 75 & 4 & - \\
\hline GFM & $16 \mathrm{~L}$ & Veenstra (2017) & 85 & 2 & - \\
\hline GFM & $17 C-721 C$ & Veenstra (2017) & 115 & 2 & - \\
\hline LanFranchi & - & $\begin{array}{l}\text { Hasan et al. } \\
(2014)\end{array}$ & $40-110$ & 3 & $\begin{array}{l}\text { Instrument } \\
\text { malfunctioned but } \\
\text { nearby instruments } \\
\text { recorded a maximum } \\
\text { pressure between } 90 \text { to } \\
110 \mathrm{kPa}\end{array}$ \\
\hline Eleonore & & Eleonore (2015) & $40-130$ & 1 & $\begin{array}{l}\text { Barricade design capacity } \\
\text { of } 140 \mathrm{kPa}\end{array}$ \\
\hline
\end{tabular}

\section{$3 \quad$ Barricade capacity modelling}

The barricade capacity modelling looked at three different components: model type, barricade shape, and barricade loading.

Three different types of models will be used to determine barricade capacity. The first type is an analytical model developed at The University of Western Australia, which can incorporate flat or arched rectangularly-shaped barricades as well as uniform or gradational loading (Zhao et al. 2020). The second model is a numerically-based 3D model of the barricade and its rock abutments. The third model is a numerical model of the actual stope (barricade, the rock surrounding the stope, and CPB within the stope). The second and third models were built and run using Itasca's FLAC3D software (Itasca Consulting Group Inc. 2020). The full stope model will use a typical NTO stope shape or the as-built shapes from either the 073L or 100D stope. The typical NTO shape will use a typical NTO barricade design shape (red wireframe in Figure 3) while the two stopes will use their actual as-built barricade shapes (Figure 3).

Historically, barricade models have been loaded uniformly, meaning that a uniform pressure was applied to the upstream surface of the barricade (Revell \& Sainsbury 2007a; Helinski et al. 2011; Oke et al. 2018). Revell \& Sainsbury (2007b) did vary the loading when trying to match their model results to actual wall failures. An exploration of barricade loading will examine two types of loading: uniform and loading developed by 
CPB rise-rate within the stope. Note that gradational (lateral earth pressure) type loading was examined but it was found that the increase in the surcharge load ultimately made the loading essentially uniform.

It has typically been accepted that an interface between the rock and the barricade is required to numerically model a barricade (Revell \& Sainsbury 2007a; Helinski et al. 2011). This sort of boundary condition is required in order to mimic the downstream compression of the barricade due to the flexure of the barricade. However, the modelling work completed by Oke et al. (2018) did not use interfaces. The numerical barricade models in this paper used interfaces between the rock and the barricade while the analytical model uses either a fully fixed or simply supported boundary condition.

The rock was assumed to behave elastically and was given typical parameters for the NTO rock mass. The rock was approximately twice as stiff as the shotcrete.

Table 2 contains the curing and UCS information for the different models. Note that each of the models was filled to around the same height prior to any additional pressure being added to the fill mass. Once additional pressure was added, the shotcrete and CPB were not aged. The shotcrete strengths between the generic and $073 \mathrm{~L}$ stope are similar while the $100 \mathrm{D}$ are stronger by approximately $5 \mathrm{MPa}$. Similarly, the CPB strengths of the generic and $073 \mathrm{~L}$ models are similar and the 100D as-built model has significantly higher CPB strengths.

Table 2 Model pouring strategy

\begin{tabular}{|c|c|c|c|c|c|}
\hline Stope & Model & $\begin{array}{l}\text { Initial } \\
\text { shotcrete } \\
\text { age }\end{array}$ & $\begin{array}{l}\text { Shotcrete age } \\
\text { when loaded } \\
\text { to capacity }\end{array}$ & $\begin{array}{l}\text { Shotcrete unconfined } \\
\text { compressive strength } \\
\text { (UCS) when loaded to } \\
\text { capacity }\end{array}$ & $\begin{array}{l}\text { Cemented } \\
\text { paste backfill } \\
\text { UCS range }\end{array}$ \\
\hline \multicolumn{6}{|c|}{ Analytical comparison } \\
\hline & Analytical & 2 days & 2 days & $20.0 \mathrm{MPa}$ & $\mathrm{n} / \mathrm{a}$ \\
\hline & Numeric & & & & \\
\hline \multicolumn{6}{|c|}{ Generic stope } \\
\hline & Uniform loading & 2 days & 2 days & $20 \mathrm{MPa}$ & $\mathrm{n} / \mathrm{a}$ \\
\hline & Tight fill & & 2.4 days & $20.7 \mathrm{MPa}$ & $2-17 \mathrm{kPa}$ \\
\hline & Typical design & & 3.3 days & $22.0 \mathrm{MPa}$ & $2-180 \mathrm{kPa}$ \\
\hline \multicolumn{6}{|l|}{ 073L } \\
\hline & Uniform loading & 1.5 days & 1.5 days & $18.9 \mathrm{MPa}$ & $\mathrm{n} / \mathrm{a}$ \\
\hline & Tight fill & & 2 days & $20.0 \mathrm{MPa}$ & $2-22 \mathrm{kPa}$ \\
\hline & As-built & & 3 days & $21.6 \mathrm{MPa}$ & $2-225 \mathrm{kPa}$ \\
\hline \multicolumn{6}{|l|}{ 100D } \\
\hline & Uniform loading & 7.5 days & 7.5 days & $25.1 \mathrm{MPa}$ & $\mathrm{n} / \mathrm{a}$ \\
\hline & Tight fill & & 8 days & $25.4 \mathrm{MPa}$ & $2-20 \mathrm{kPa}$ \\
\hline & As-built & & 10.5 days & $26.4 \mathrm{MPa}$ & $2-440 \mathrm{kPa}$ \\
\hline
\end{tabular}




\subsection{Modelling results}

\subsubsection{Comparison of analytical and numerical models}

The analytical model is an elastic model that can model both flat and arched rectangular shaped barricades. It uses either a fully fixed or simply supported boundary condition. The model geometries used were flat and arched (same arch as NTO's prefabricated framework) that would fit into a $6 \times 5 \mathrm{~m}$ drive. FLAC3D models of the equivalent geometry were also created. Each analytical model used the equivalent elastic parameters to that of the FLAC3D model, which was strain softening. Figure 7 compares the results of the analytical and numerical models. Note that only a simply supported arched was modelled analytically due to the complexity of modelling a fully fixed arch. This model was only run to a barricade loading pressure of $200 \mathrm{kPa}$ (solid orange line on the 'arched plots'). This was extrapolated to the loading pressures seen in the FLAC3D model (dashed orange line).

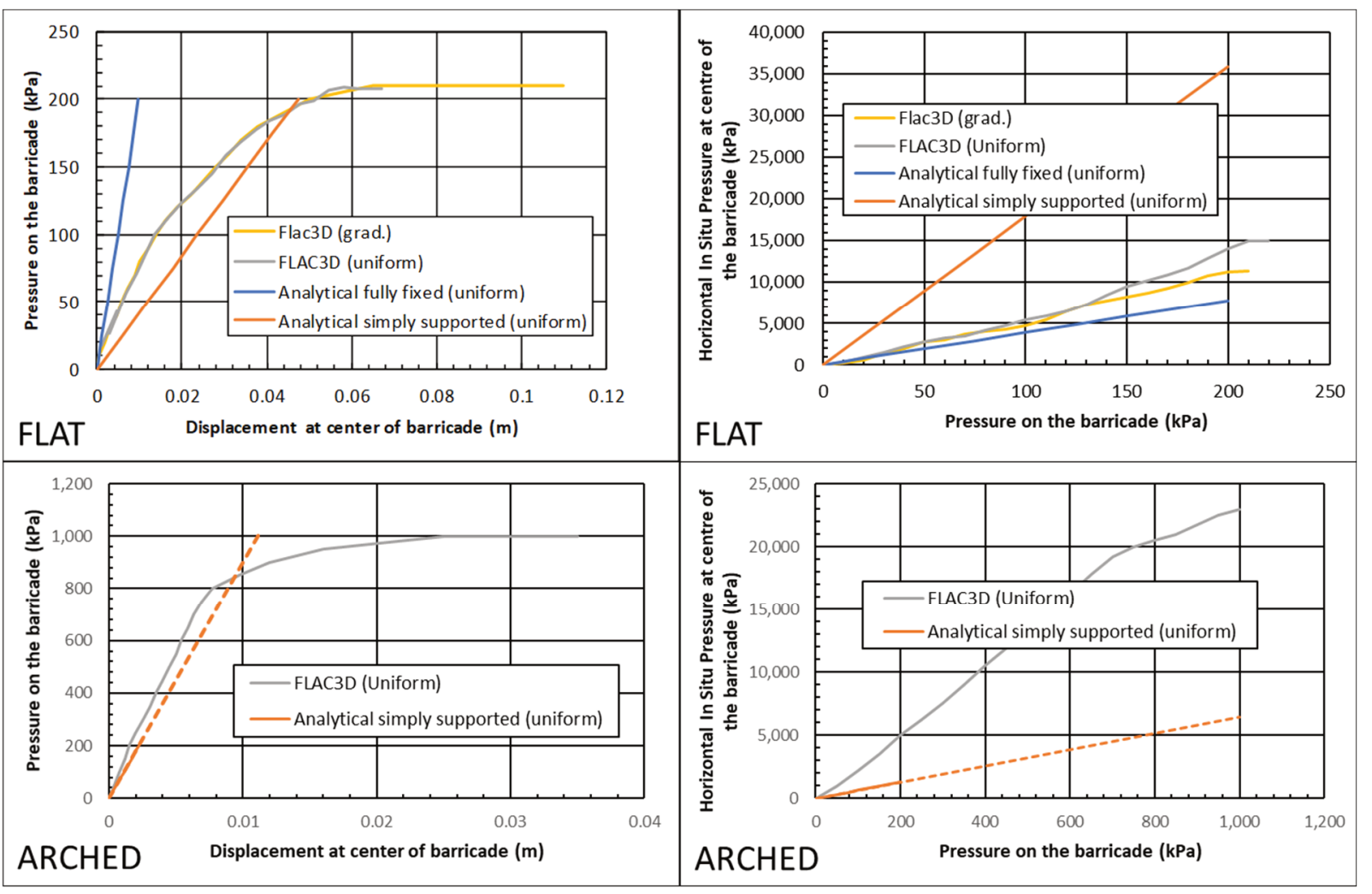

Figure 7 Comparison of results obtained from the flat and arched analytical and numerical models

The displacement versus barricade loading pressure plots show that the FLAC3D model has a response that is between the fully fixed and simply supported analytical models, which was expected. The in situ barricade pressure versus barricade loading pressure plots shows that there was reasonably good correlation between the fully fixed flat analytical model and the FLAC3D results but significantly less correlation between the simply supported models and the FLAC3D model.

\subsubsection{Numerical modelling results}

The $073 \mathrm{~L}$ as-built capacity barricade model results are presented in Figure 8. This figure contains contour plots of the maximum compressive stress, cohesive strength, and tensile strength associated with the increased loading shown on the graph. In all of the contour plots, red means the maximum value (of either compressive stress, cohesion, or tension) while blue means that these values are zero. For example, a zone in the cohesion plot that is red is at the maximum cohesion value for that model. When that zone's maximum strength is reached, due to increased stress, it fails and its strength degrades, indicated by colour changes to 
blue. Areas of coalesced blue zones in the cohesion and tension plots are analogous to areas where cracking would occur.

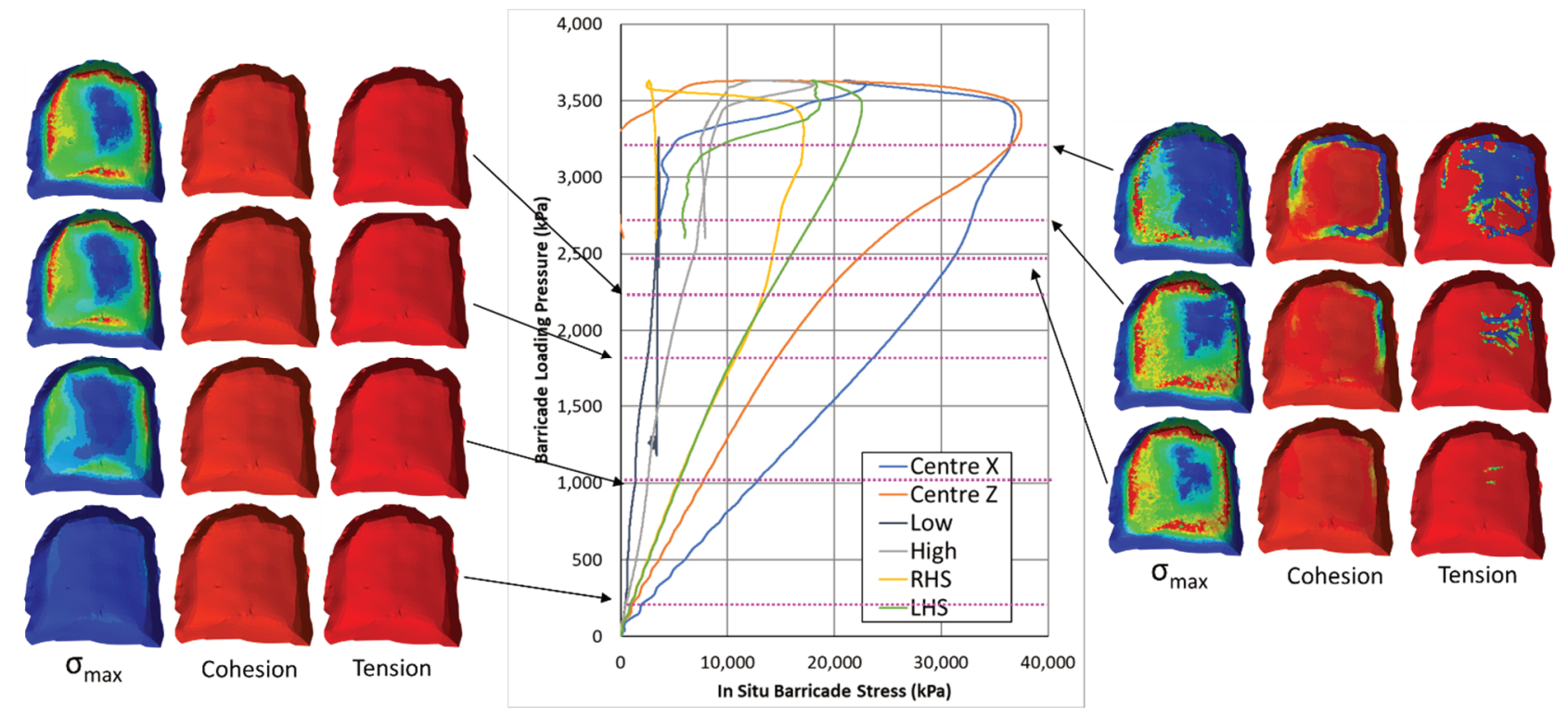

Figure 8 Model plots of maximum compressive stress, cohesion, and tension with increased loading (shown in the graph) for the $073 \mathrm{~L}$ as-built capacity model

The in situ stress gain below $2,250 \mathrm{kPa}$ of loading pressure is fairly linear at all of the measured locations and the barricade has no strength degradation. However, above 2,250 kPa of load pressure the loading rates change as the barricade starts to yield. This corresponds to the decrease in cohesive strength and the initiation of tensile cracking in the upper left quadrant of the barricade. Areas that are being damaged shed stress to more competent areas, hence why some of the measurement areas increase and some decrease. Note that actual instrumentation data is well below the lowest dashed pink line.

Complete failure at the monitoring location is shown by a rapid decrease of the in situ barricade stress. This happens first at the Low and RHS locations, followed by the Centre Z, Centre X, LHS, and High locations. This sequence is also shown in the strength plots with the upper right quadrant showing damage first and then the damage migrates around the perimeter.

All of the barricade models exhibited similar loading trends as seen in the 073L. These trends are summarised in Table 3. It was found that yielding behaviour initiated at similar stress values at all of the measurement locations. However, the locations of failure varied between the models, with failure being initiated at the centre of the barricade in the generic models and at the abutments of the as-built models (the RHS or LHS of the drive for the $073 \mathrm{~L}$ and $100 \mathrm{D}$, respectively). 


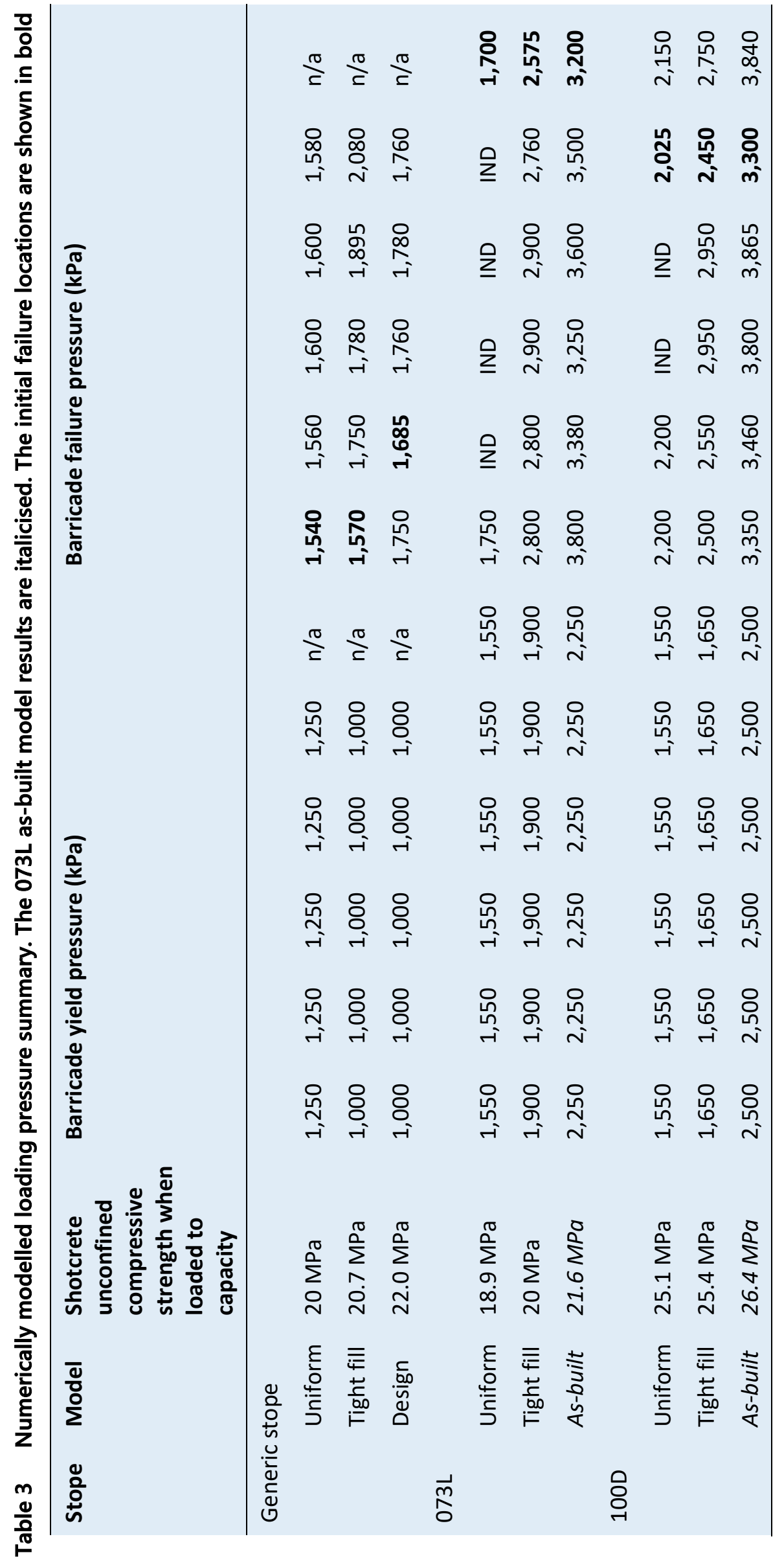


The uniformly-loaded barricade models failed at lower pressures than the rise-rate loaded barricades. It was also found that generic stope models failed at lower loading pressures than the as-built models. This is attributed to the differences in loading and the geometric shape differences between the generic and the as-builts models.

In order to load the barricades to capacity, it was necessary to load the tight fill and as-built models to a higher pressure than what is possible using gravity. This was done by applying sequentially greater pressure to the CPB within the stope. This pressure would then migrate down the drive and load the barricade. Figure 9 shows the required vertical pressures at the bottom of the $073 \mathrm{~L}$ stope to load its barricade to failure. Note that this model takes into account the strength gain of both the shotcrete and CPB.

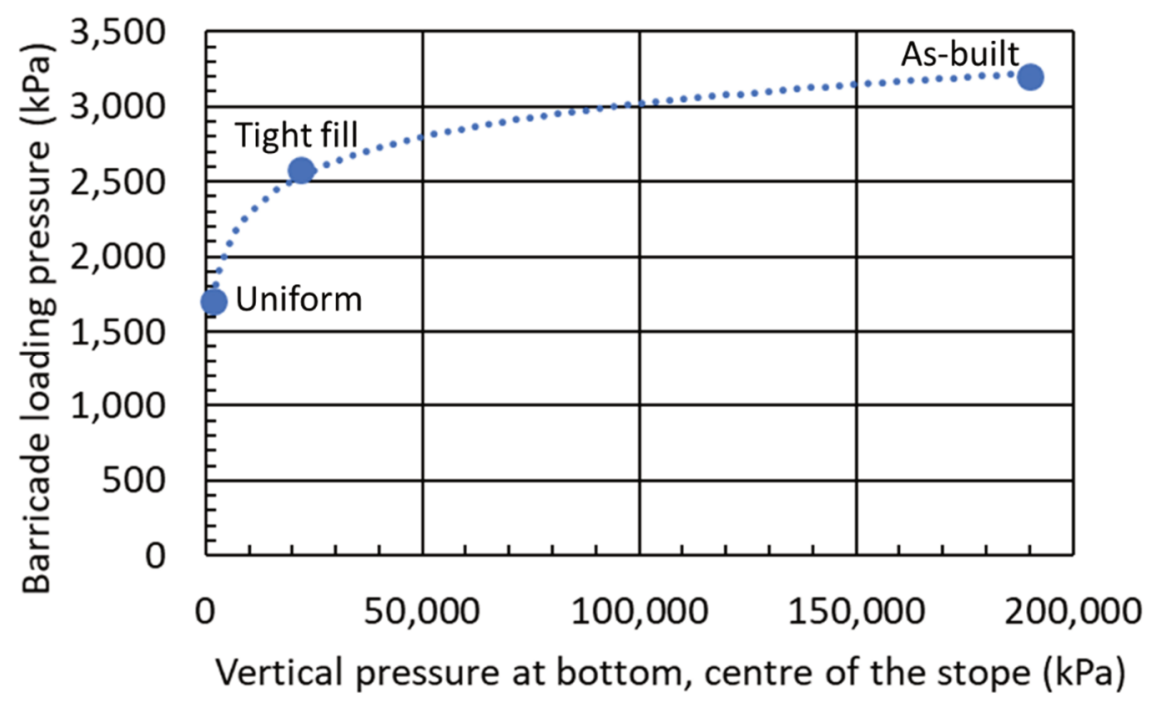

Figure 9 The required vertical pressure at bottom, centre of the 073L stope for the barricade to be loaded to failure

The results presented in Figure 9 show that, for NTO CPB anyway, it would not be possible to pressurise the CPB in the tight fill $(22 \mathrm{MPa})$ or as-built (190 MPa) configuration enough to reach the capacity of the barricade. However, NTO CPB generally exhibits quick strength gain (100 kPa in 12 to 18 hours), a relatively short isotropic stress period ( 3 hours), and relatively slow CPB rise rates $(<15 \mathrm{~cm} / \mathrm{hr})$. It would be possible to over-pressurise a barricade if the stope was filled quickly with CPB that had a long isotropic stress period and a slow rate of strength gain.

Figure 10 shows vertical cross-sections of the loading pressures model plots for the $073 \mathrm{~L}$ stope (the barricade is located on the LHS of the plots). All three plots show stress arching within the drive and the variable loading on the barricade. Note that this loading is three-dimensional and is affected by the shape of the bottom of the stope, drive, and barricade. It is common practice to place a waste rock berm within the stope's undercut to prevent access to the stope as well as preventing rocks from entering the undercut. The effect of this berm is shown in the $073 \mathrm{~L}$ plots where the wall is being protected from significantly higher stresses within the stope. 


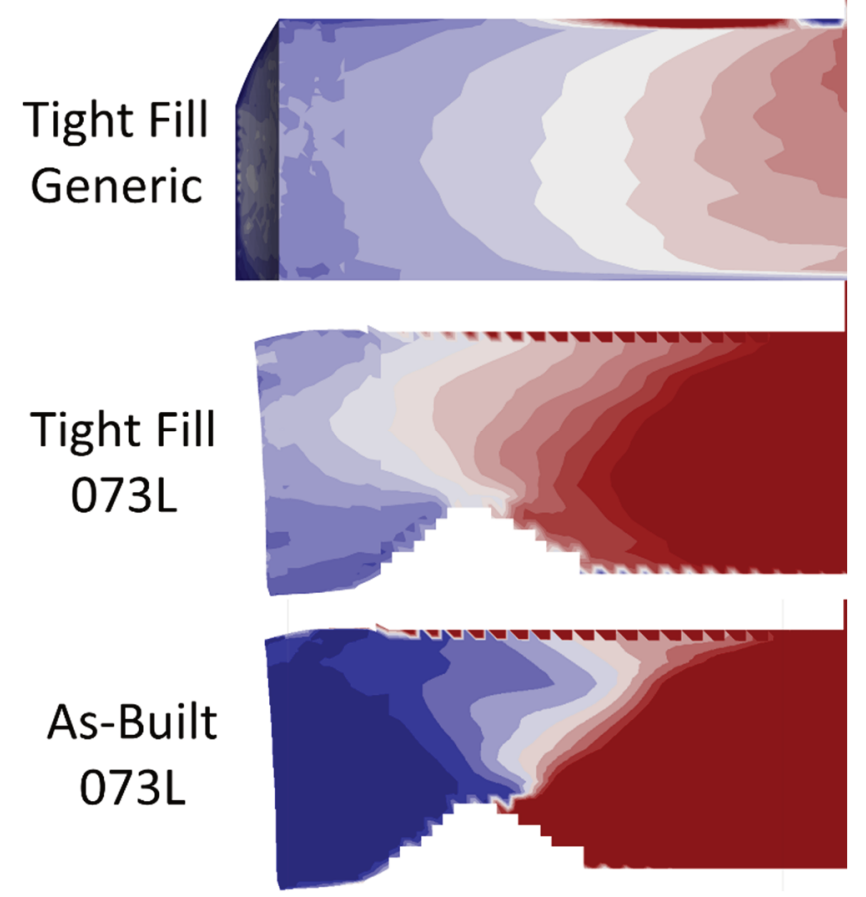

Figure 10 Vertically oriented contour plots of the stress that is perpendicular to the barricade. These plots show the stress arching within the stope and the impact of the brow bund on the wall loading

A barricade's capacity is also affected by where the failure takes place. Figure 11 compares cohesive strength contour plots for the uniformly-loaded generic, the tight filled generic, and the tight filled 073L models. There are two views: looking upstream and cross-sectional plan view across the black line. These plots show that, despite having different loading mechanisms, the two generic models show similar failure patterns along the centre and abutments. However, the $073 \mathrm{~L}$ as-built model shows a different failure pattern with failure occurring at the transition between the barricade arch and abutment. The cross-section view of the 073L is of particular interest as it shows the misalignment discussed earlier but also that the shotcrete is significantly thinner on that side.

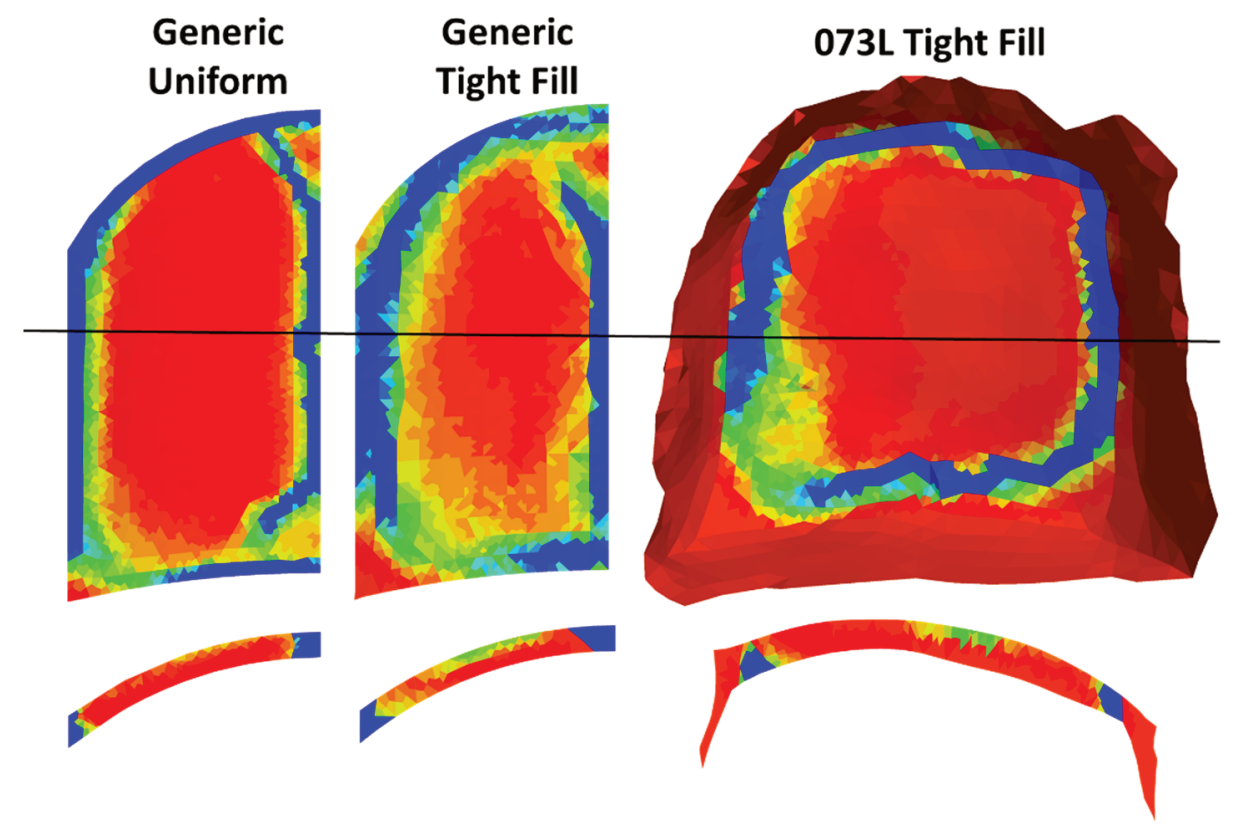

Figure 11 Upstream and cross-sectional plan plots of the cohesive strength for the uniformly and tight fill loaded generic barricade, and the $073 \mathrm{~L}$ tight fill loaded model 
The different failure location between the models has several implications. The first is that it suggests that the modelled interface between the rock and barricade is not required as the shotcrete fails within itself and that the abutments do not exhibit any damage. However, this assertion would need to be examined further with different rock mass stiffnesses and abutment conditions. It also suggests that the use of shear pins (rebar bolts that are installed to prevent the barricade from 'sliding' down the drive) are not needed. However, what is most apparent is that the size of the failure has been decreased. This decrease would cause the barricade to fail at higher pressure loads which is what was observed in this modelling exercise.

Finally, both as-built walls were misaligned to the right. It was anticipated that the RHS of the barricade would experience higher stress and be the initial point of failure. The 073L barricade fulfilled this expectation. However, the 100D barricade did not. It was found in subsequent analysis that both failure locations were due to thin spots in the shotcrete. Figure 12 shows horizontal cross-sections for each model taken at where initial point of failure originated. The shotcrete thickness at both points is approximately $30 \mathrm{~cm}$ in the $073 \mathrm{~L}$ model and $20 \mathrm{~cm}$ in the 100D model. The modelling shows that the failure of the as-built models initiates where the wall is thinnest and then propagates away from this location following the junction of the shotcrete arch and abutments.

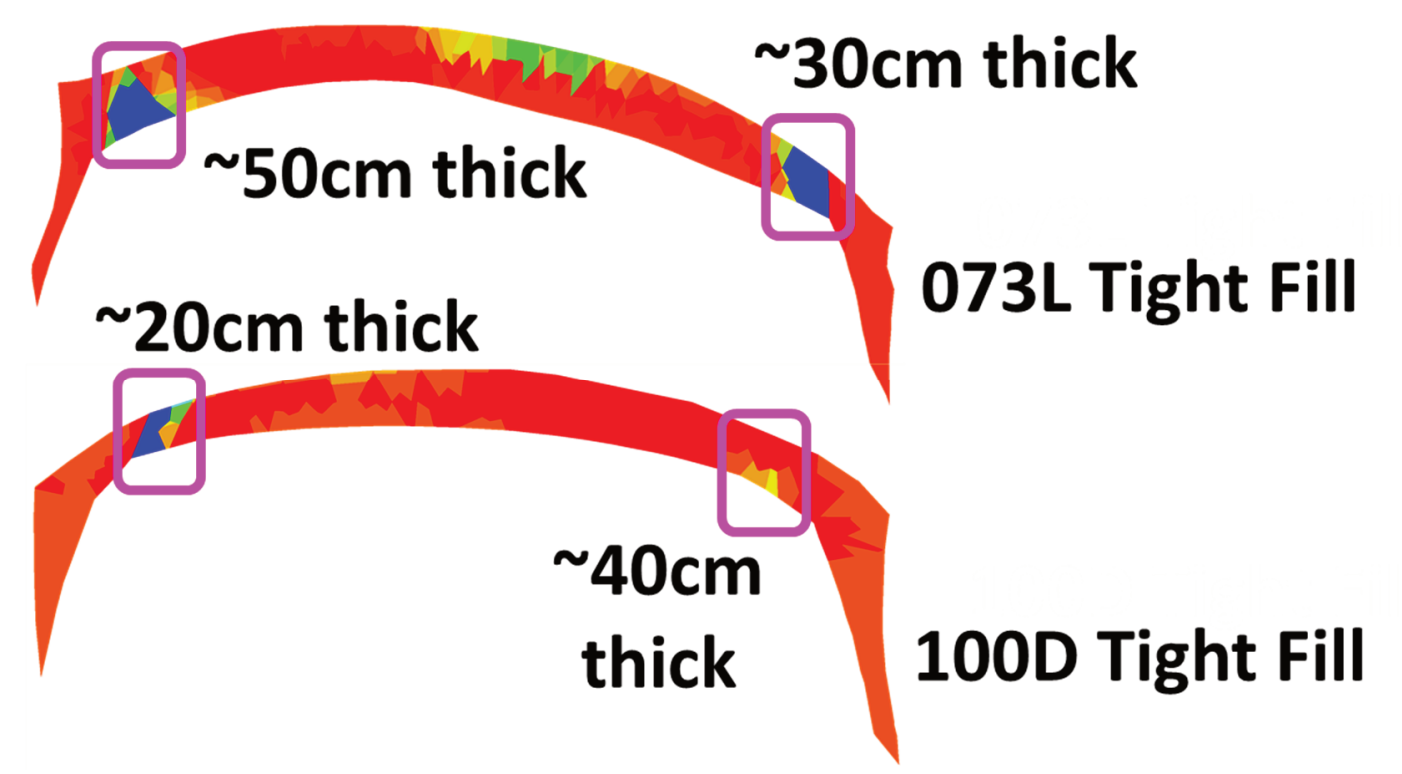

Figure 12 Horizontal cross-sections across the initial failure location for the 073L and 100D tight fill barricade models

\section{$4 \quad$ Conclusions and moving forwards}

This paper initially presented the results of an instrumentation study that looked at linking the lateral barricade pressure, measured in situ within the CPB just upstream of the barricade, with internal barricade stresses, measured in situ with the barricade's shotcrete. This included the use of a laser scanner to generate as-built scans of the barricade and the drive. The authors were able to calibrate a numerical model that linked the strength gain behaviour of the CPB and shotcrete to the loading observed within the stopes. However, the actual loading of the barricades was low (around $60 \mathrm{kPa}$ ) during normal CPB placement of CPB into the stopes. These loads were not close to the barricade's capacity.

A comparison of a numerical and analytical model was conducted. The analytical model is capable of elastically modelling flat and arched barricades. A comparison of the numerical and analytical model results showed some good correlations for the flat barricade models. However, more work is required on the arched model.

In order to examine the capacity of the barricades, the loading model discussed previously was used to load the barricades to capacity. These results were then compared to uniformly-loaded models. This found that 
the uniformly-loaded models failed at lower pressures than the gradationally loaded models. This failure pressure discrepancy is primarily attributed to shape of the barricade with the barricade's loading mechanism having some influence. Note that these results are pertinent only to the stopes filled at Tanami and were only obtained because of the large amount of data and analysis that has been conducted at that site. Any operation looking to change its barricade design needs to complete a comprehensive in situ monitoring program.

The shape of the walls was found to be of primary importance. The failure of the generic models initiated at the centre of the barricade and then at the abutment between the rock and the shotcrete. However, in the as-built models, these abutments were reinforced with additional shotcrete. This reinforcement means that the as-built barricade models failed at the transition between the thicker shotcrete abutment and the rest of the arch. This effectively makes the size of the wall smaller, which increases its capacity.

The as-built barricade's failure initiation point was also different than the generic models. The initiation of failure for both the as-built barricades started where the shotcrete was thinnest. The failure then migrated around the outside of the barricade following the transition between the thicker shotcrete abutment and the rest of the arch mentioned above.

Additionally, the non-uniform loading due the stress arching effect through the drive reduces the load on the barricade at the abutments of the barricade. The nature of this loading means that there is higher loading somewhere in the middle of the barricade compared to that on the abutments.

Finally, this work also highlighted the impact that the time-dependent CPB parameters has on barricade capacity. The modelling showed that it is unlikely that an NTO barricade could be failed through over pressurisation. However, further in situ monitoring and numerical modelling work is required, particularly for tight filling situations.

Moving forwards, in order to examine the comment above, NTO plans to instrument more stopes in a similar manner to what was completed in this paper. However, the focus will be on installing the instruments in tight filled overcuts instead of the traditional gravity filling undercuts.

\section{Acknowledgement}

The authors would like to thank the Mansfield Gadd and NTO paste crew, as well as NTO technical services personnel, specifically Braden Clarke, Adam Zajac, and Hamish Rose for their help during instrument installation.

\section{References}

Clough, GW, Iwabuchi, J, Shafii, RN \& Kuppusamy, T 1989, 'Influence of cementation on liquefaction of sands', Journal of Geotechnical Engineering, vol. 115, no. 8, pp. 1102-1117.

Eleonore 2015, Eleonore Paste Backfill Barricade Monitoring, internal communication, Goldcorp, Quebec.

Hasan, A, Suazo, G, Doherty, JP \& Fourie, AB 2014, 'In situ measurements of cemented paste backfilling in an operating stope at Lanfranchi Mine', Proceedings of the 11th International Symposium on Mining with Backfill, Australian Centre for Geomechanics, Perth, pp. 327-336.

Helinski, M, Wines, D, Revell, M \& Sainsbury, D 2011, 'Critical factors influencing the capacity of arched fibrecrete bulkheads and waste rock barricades', Proceedings of the 10th International Symposium on Mining with Backfill, Southern African Institute of Mining and Metallurgy, Cape Town, pp. 293-304.

Itasca Consulting Group Inc. 2020, FLAC3D: Fast Lagranian Analysis of Continua in 3 Dimensions, version 6.0, ICG, Minneapolis.

Oke, J, Thompson, BD, Grabinsky, MW, Bawden, WF \& Lausch, P 2018, 'Backfill barricade design: practical experiences and recommendations', Proceedings of the 52nd US Rock Mechanics/Geomechanics Symposium, American Rock Mechanics Association, Seattle.

Revell, M \& Sainsbury, D 2007a, 'Advancing paste fill bulkhead design using numerical modeling', MineFill 2007: Proceedings of the 9th International Symposium on Mining with Backfill, Canadian Institute of Mining, Montreal.

Revell, M \& Sainsbury, D 2007b, 'Paste bulkhead failures', Proceedings of the 9th International Symposium on Mining with Backfill, Canadian Institute of Mining, Montreal.

Saw, HA, Villaescusa, E, Windsor, CR \& Thompson, AG 2009, 'Non-linear, elastic-plastic response of steel fibre reinforced shotcrete to uniaxial and triaxial compression testing', Proceedings of Shotcrete for Underground Support XI, Engineering Conferences International, Davos. 
Thompson, BD, Grabinsky, MW, Veenstra, R \& Bawden, WF 2011a, 'In situ pressures in cemented paste backfill - a review of fieldwork from three mines', in R Jewell \& AB Fourie (eds), Paste 2011: Proceedings of the 14th International Seminar on Paste and Thickened Tailings, Australian Centre for Geomechanics, Perth, pp. 491-503, https://doi.org/10.36487/ACG_rep/ 1104_42_Thompson

Thompson, BD, Grabinsky, MW \& Bawden, WF 2011b, 'In situ monitoring of cemented paste backfill pressure to increase backfill efficiency', Rock Engineering, Canadian Institute of Mining, vol. 2, no. 4, pp. 199-209.

Thompson, BD, Bawden, WF \& Grabinsky, MW 2012, 'In situ measurements of cemented paste at the Cayeli Mine', Canadian Geotechnical Journal, NRC Research Press, vol. 49, pp. 755-772.

Veenstra, RL 2013, A Design Procedure for Determining the In Situ Stresses of Early Age Cemented Paste Backfill, PhD thesis, University of Toronto, Toronto.

Veenstra, RL 2017, 'In situ instrumentation of a cemented paste backfill stope at George Fisher Mine', MineFill 2017: Proceedings of the 12th International Conference of Mining with Backfill, SME, Denver, pp. 327-336.

Zhao, X, Fourie, AB, Veenstra, RL \& Qi, CC 2020, 'Safety of barricades in cemented paste backfill stopes', International Journal of Minerals, Metallurgy and Materials, vol. 27, pp. 1054-1064, https://doi.org/10.1007/s12613-020-2006-3 